\title{
Critical Factors that Affecting Efficiency of Solar Cells
}

\section{Furkan Dinçer, Mehmet Emin Meral}

University of Yuzuncu Yil, Department of Electrical and Electronics Engineering, Van, Turkey.

Email: furkandincer@yyu.edu.tr, emeral@yyu.edu.tr

Received February $17^{\text {th }}, 2010$; revised May $7^{\text {th }}, 2010$; accepted May $8^{\text {th }}, 2010$.

\begin{abstract}
A solar cell or photovoltaic cell is a device which generates electricity directly from visible light. However, their efficiency is fairly low. So, the solar cell costs expensive according to other energy resources products. Several factors affect solar cell efficiency. This paper presents the most important factors that affecting efficiency of solar cells. These effects are cell temperature, MPPT (maximum power point tracking) and energy conversion efficiency. The changing of these factors improves solar cell efficiency for more reliable applications.
\end{abstract}

Keywords: Solar Cell, Efficiency, Cell Factor, Cell Temperature

\section{Introduction}

Solar cells have seen remarkable improvements since the first issue of the journal Solar Energy Materials in 1979. The photovoltaic (PV) field has given rise to a global industry capable of producing many gigawatts $(\mathrm{GW})$ of additional installed capacity per year [1].

The problems with energy supply and use are related not only to global warming but also to such environmental concerns as air pollution, acid precipitation, ozone depletion, forest destruction, and radioactive substance emissions. To prevent these effects, some potential solutions have evolved including energy conservation through improved energy efficiency, a reduction in fossil fuel use and an increase in environmentally friendly energy supplies. Among them, the power generation with solar cells system has received great attention in research because it appears to be one of the possible solutions to the environmental problem [2].

Solar Energy is energy that comes from the sun. The energy uses by solar cells that convert sunlight into direct current electricity. Solar cells are composed of various semi conducting materials. Semiconductors are materials, which become electrically conductive when supplied with light or heat, but which operate as insulators at low temperatures.

When photons of light fall on the cell, they transfer their energy to the charge carriers. The electric field across the junction separates photo-generated positive charge carriers (holes) from their negative counterpart (electrons). In this way an electrical current is extracted once the circuit is closed on an external load.

Several factors affect solar cell efficiency. This paper examines the factors that affecting efficiency of solar cells according to scientific literature. These factors are changing of cell temperature, using the MPPT with solar cell and energy conversion efficiency for solar cell.

\section{Characterization of Solar Cells}

It is quite generally defined as the emergence of an electric voltage between two electrodes attached to a solid or liquid system upon shining light onto this system. Practically all photovoltaic devices incorporate a $\mathrm{p}-\mathrm{n}$ junction in a semiconductor across which the photovoltage is developed. These devices are also known as solar cells. A cross-section through a typical solar cell is shown in Figure 1. The semiconductor material has to be able to absorb a large part of the solar spectrum. Dependent on the absorption properties of the material the light is absorbed in a region more or less close to the surface. When light quanta are absorbed, electron hole pairs are generated and if their recombination is prevented they can reach the junction where they are separated by an electric field [3].

The photoelectric effect was first noted by a French physicist, Edmund Bequerel, in 1839, who found that certain materials would produce small amounts of electric current when exposed to light $[4,5]$. The theory of the solar cell is the solar effect of semiconductor material. The solar effect is a phenomenon that the semiconductor material absorbs the solar energy, and then the electron-hole excitated by the photon separates and produces electro- 


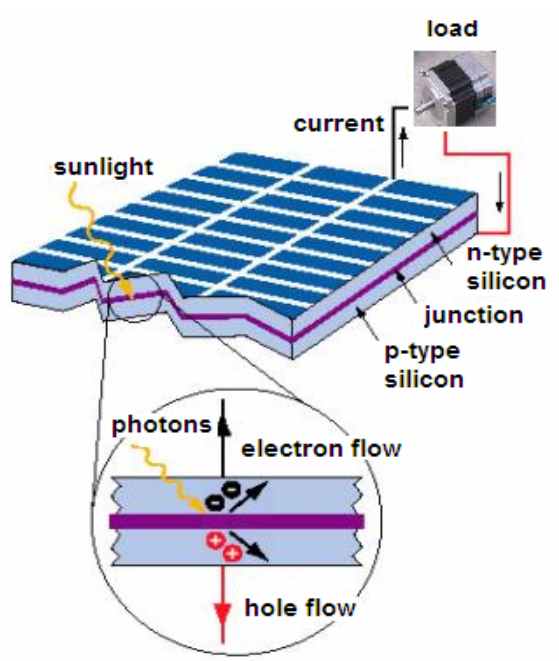

Figure 1. A schematic of the layers of a typical PV cell [4]

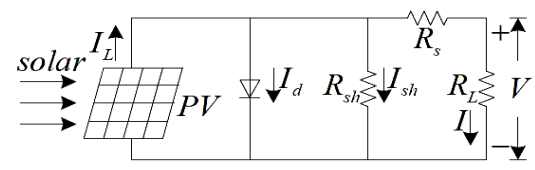

Figure 2. The equivalent circuit of the solar cell [6]

motive force. The $I-V$ characteristic of the solar cell changes with the sunshine intensity $S\left(\mathrm{~W} / \mathrm{m}^{2}\right)$ and cell temperature $t\left({ }^{\circ} \mathrm{C}\right)$, that is $I=f(V, S, t)$. According to the theory of electronics, when the load is pure resistance, the actual equivalent circuit of the solar cell is as Figure 2 [6]. $I_{L}$ is current supplied by solar cell.

$$
I=I_{L}-I_{0}\left[\exp \left(\frac{q\left(V+I R_{S}\right)}{A k T}\right)-1\right]-\frac{V+I R_{S}}{R_{S H}}
$$

where [6], $I_{d}$, the junction current of the diode

$$
I_{d}=I_{0}\left[\exp \left(\frac{q\left(V+I R_{S}\right)}{A k T}\right)-1\right]
$$

$I$, the load current

$I_{L}$, the photovoltaic current,

$I_{0}$, the reverse saturation current

$q$, electronic charge,

$k$, boltzmann constant,

$T$, absolute temperature, $A$, factor of the diode quality

$R_{S}$, series resistance,

$R_{S H}$, parallel resistance

Another important parameter is open circuit voltage $V_{O C}$;

$$
V_{O C}=\frac{k T}{q} \ln \left(\frac{I_{L}}{I_{0}}+1\right) \approx \frac{k T}{q} \ln \left(\frac{I_{L}}{I_{0}}\right)
$$

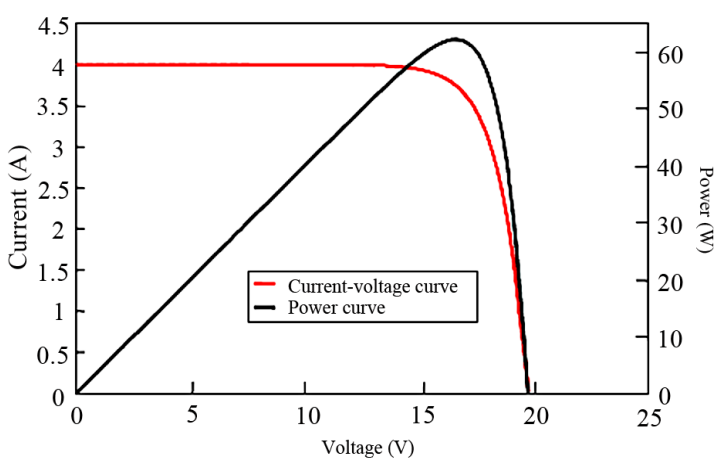

Figure 3. Typical I-V characteristic of a crystalline silicon module with the variation of power [7]

Figure 3 shows an I-V characteristic together with the power curve, to illustrate the position of the maximum power point [7].

\section{Solar Cells Efficiency Factors}

\subsection{Cell Temperature}

As temperature increases, the band gap of the intrinsic semiconductor shrinks, and the open circuit voltage $\left(V_{O C}\right)$ decreases following the $\mathrm{p}-\mathrm{n}$ junction voltage temperature dependency of seen in the diode factor $q / k T$. Solar cells therefore have a negative temperature coefficient of $V_{O C}$ $(\beta)$. Moreover, a lower output power results given the same photocurrent because the charge carriers are liberated at a lower potential. Using the convention introduced with the Fill Factor calculation, a reduction in $V_{O C}$ results in a smaller theoretical maximum power $P_{\max }=I_{S C} \times$ $V_{O C}$ given the same short-circuit current $I_{S C}$ [8].

As temperature increases, again the band gap of the intrinsic semiconductor shrinks meaning more incident energy is absorbed because a greater percentage of the incident light has enough energy to raise charge carriers from the valence band to the conduction band. A larger photocurrent results; therefore, Isc increases for a given insolation, and solar cells have a positive temperature coefficient of $I_{S C}(\alpha)$ [8].

Figure 4 shows the I-V and $\mathrm{P}-\mathrm{V}$ characteristics at the constant illumination when the temperature changes [9]. Temperature effects are the result of an inherent characteristic of crystalline silicon cell-based modules. They tend to produce higher voltage as the temperature drops and, conversely, to lose voltage in high temperatures. Any solar panel or system derating calculation must include adjustment for this temperature effect [10].

\subsection{Energy Conversion Efficiency}

A solar cell's energy conversion efficiency ( $\eta$, “eta"), is 


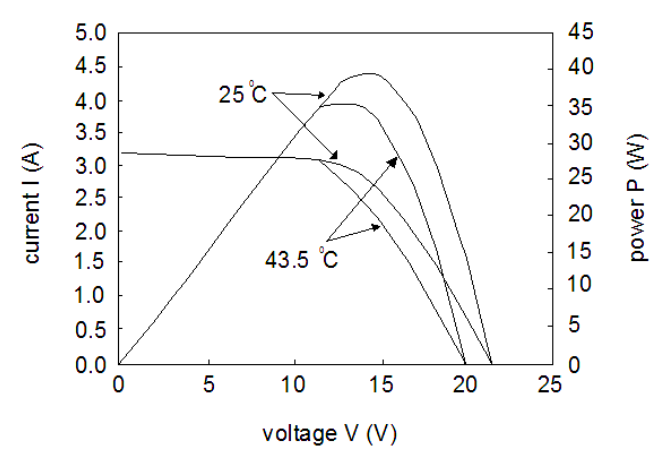

Figure 4. I-V and P-V characteristics of solar cell module [9]

the percentage of power converted (from absorbed light to electrical energy) and collected, when a solar cell is connected to an electrical circuit. This term is calculated using the ratio of the maximum power point, $P_{m}$, divided by the input light irradiance $\left(E\right.$, in $\left.\mathrm{W} / \mathrm{m}^{2}\right)$ under standard test conditions and the surface area of the solar cell $\left(A_{c}\right.$ in $\left.\mathrm{m}^{2}\right)[11]$.

$$
\eta=\frac{P_{m}}{E x A_{c}}
$$

The efficiency of energy conversion is still low, thus requiring large areas for sufficient insulation and raising concern about unfavorable ratios of energies required for cell production versus energy collected [12]. In order to increase the energy conversion efficiency of the solar cell by reducing the reflection of incident light, two methods are widely used. One is reduction of the reflection of incident light with an antireflection coating, and the other is optical confinements of incident light with textured surfaces. They showed that the transformation of the wavelength of light could significantly enhance the spectral sensitivity of a silicon photodiode from the deep UV and through most of the visible region. [13].

The solar module has a different spectral response depending on the kind of the module. Therefore, the change of the spectral irradiance influences the solar power generation [14]. The solar spectrum can be approximated by a black body of $5900 \mathrm{~K}$ which results in a very broad spectrum ranging from the ultraviolet to the near infrared. A semiconductor, on the other hand can only convert photons with the energy of the band gap with good efficiency. Photons with lower energy are not absorbed and those with higher energy are reduced to gap energy by thermalization of the photo generated carriers. Therefore, the curve of efficiency versus band gap goes through a maximum as seen from Figure 5 [3].

\subsection{Maximum Power Point Tracking}

Currently, the electricity transformation efficiency of the solar cells is very low that reach about $14 \%$. The efficiency of solar cells should be improved with various methods. One of them is maximum power point tracking

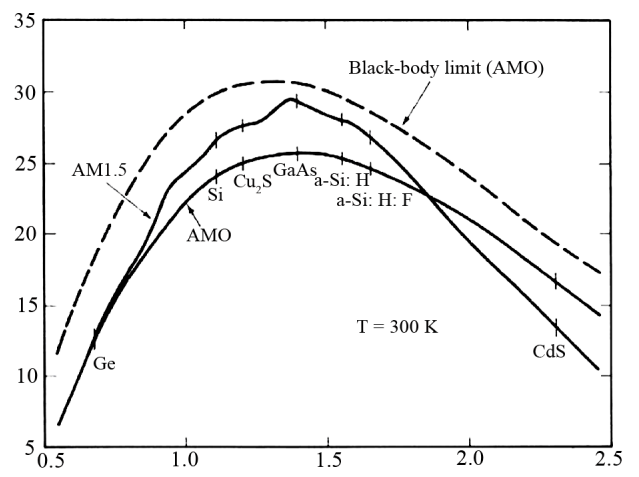

Figure 5. Dependency of the conversion efficiency on the semiconductor band gap [3]

(MPPT) which is an important method. The MPPT operates with DC to DC high efficiency converter that presents an optimal and suitable output power.

The resulting I-V characteristic is shown in Figure 5. The photo generated current $I_{L}$ is equal to the current produced by the cell at short circuit $(V=0)$. The open circuit Voltage $V_{O C}$ (when $\left.I=0\right)$ can easily be obtained as [15].

No power is generated under short or open circuit. The maximum power $\mathrm{P}$ produced by the conversion device is reached at a point on the characteristic. This is shown graphically in Figure 6 where the position of the maximum power point represents the largest area of the rectangle shown. One usually defines the fill-factor $f f$ by [15].

$$
f f=\frac{P_{\max }}{V_{O C}}=\frac{V_{m} I_{m}}{V_{O C} I_{l}}
$$

where, $V_{m}$ and $I_{m}$ are the voltage and current at the maximum power point.

When the output voltage of the photovoltaic cell array is very low, the output current changes little as the voltagechanges, so the photovoltaic cell array is similar to the constant current source; when the Voltage is over a critical value and keeps rising, the current will fall sharply, now the photovoltaic cell array is similar to the constant volt-

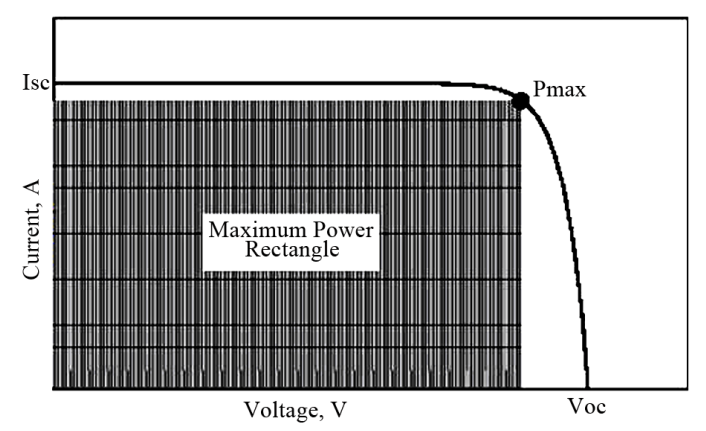

Figure 6. The I-V characteristic of an ideal solar cell [15] 
age source. As the output voltage keeps rising, the output power has a maximum power point. The function of the maximum power tracker is to change the equivalent load take by the photovoltaic cell array, and adjust the working point of the photovoltaic cell array, in order that the photovoltaic cell array can work on the maximum power point when the temperature and radiant intensity are both changing [6].

\section{Conclusions}

This paper examine factors that affecting efficiency of solar cells. These are changing of cell temperature, using the MPPT with solar cell and energy conversion efficiency for solar cell.

Temperature effects are the result of an inherent characteristic of solar cells. They tend to produce higher voltage as the temperature drops and, conversely, to lose voltage in high temperatures. The energy conversion efficiency is increased by reducing the reflection of incident light. The function of the maximum power tracker is to change the equivalent load take by the solar cell array, and adjust the working point of the array, in order to improve the efficiency.

Changing of these factors is very critical for solar cell efficiency. The optimum factors make it possible to get the great benefits of solar electricity at a much lower cost.

\section{REFERENCES}

[1] "Reporting Solar Cell Efficiencies in Solar Energy Materials and Solar Cells," Solar Energy Materials \& Solar Cells, Elsevier Science, 2008.

[2] R.-J. Wai, W.-H. Wang and C.-Y. Lin, "High-Performance Stand-Alone Photovoltaic Generation System," Proceedings of IEEE Transactions on Industrial Electronics, Vol. 55, No. 1, January 2008.

[3] A. Goetzberger, C. Hebling and H.-W. Schock, "Photovoltaic Materials, History, Status and Outlook," Materials
Science and Engineering, Vol. 40, 2003, pp. 1-46.

[4] February 2010. http://www.rise.org.au/info/Education/ SAPS/sps003.html

[5] February 2010. http://science.nasa.gov/headlines/y2002/ solarcells.html

[6] X.-J. Ma, J.-Y. Wu, Y.-D. Sun and S.-Q. Liu, "The Research on the Algorithm of Maximum Power Point Tracking in Photovoltaic Array of Solar Car," Vehicle Power and Propulsion Conference, IEEE, 2009, pp. 1379-1382.

[7] N. M. Pearsall and R. Hill, "Photovoltaic Modules, Systems and Applications," In: M. D. Archer, and R. Hill, Eds., Clean Electricity from Photovoltaics, World Science, Vol. 1, 2002, pp. 1-42.

[8] February 2010. http://alumni.media.mit.edu/ nate/AES/ PV_Theory_II.pdf

[9] Y. Suita and S. Tadakuma, "Driving Performances of Solar Energy Powered Vehicle with MPTC," IEEE, 2006.

[10] February 2010. http://www.altestore.com/howto/SolarPower-Residential-Mobile-PV/Off-Grid-Solar-Systems/El ectrical-Characteristics-of-Solar-Panels-PV-Modules/a87/

[11] February 2010. http://en.wikipedia.org/wiki/Solar_cell

[12] H. J. Queisser and J. H. Werner, "Principles and Technology of Photovoltaic Energy Conversion," Solid-State and Integrated Circuit Technology, October 1995, pp. 146-150.

[13] T. Maruyama, Y. Shinyashiki and S. Osako, "Energy Conversion Efficiency of Solar Cells Coated with Fluorescent Coloring Agent," Solar Energy Materials \& Solar Cells, Elsevier Science, 1998.

[14] M. Nishihata, Y. Ishihara and T. Todaka, "Presumption of Solar Power Generation Corresponding to the Change of Solar Spectrum, Photovoltaic Energy Conversion," Proceedings of the 2006 IEEE 4th World Conference, Vol. 2, May 2006, pp. 2168-2171.

[15] S. Capar, "Photovoltaic Power Generation for Polycrystalline Solar Cells and Turning Sunlight into Electricity Thesis," Engineering Physics, University of Gaziantep, July 2005. 